\title{
Long-term Observations of Atmospheric Halogenated Organic Trace Gases
}

\author{
Stefan Reimann*, Martin K. Vollmer, Matthias Hill, Paul Schlauri, Myriam Guillevic, Dominik Brunner, \\ Stephan Henne, Dominique Rust, and Lukas Emmenegger
}

\begin{abstract}
CFCs (chlorofluorocarbons) and other strong ozone-depleting halogenated organic trace gases were used in numerous industrial, household and agriculture applications. First atmospheric measurements of CFCs were performed in the 1970s, well ahead of the detection of the ozone hole in the 1980s. The continuous observation of these ozone-depleting substances (ODSs) is crucial for monitoring their global ban within the Montreal Protocol. In addition, also HFCs (fluorinated hydrocarbons) are measured, which were introduced as substitutes of ODSs and are potent greenhouse gases. Since 2000, Empa continuously measures more than 50 halogenated trace gases at the high-Alpine station of Jungfraujoch (3850 m asl) as part of the global AGAGE network (Advanced Global Atmospheric Gases Experiment). Jungfraujoch is the highest location worldwide where such measurements are performed, and the site where several of these compounds were measured in the atmosphere for the first time. The measurements at Jungfraujoch and at other globally well-positioned sites serve as an early warning system, i.e. before potentially harmful halogenated organic substances can accumulate and detrimentally affect the natural environment.
\end{abstract}

Keywords: Chlorofluorocarbons · Hydrochlorofluorocarbons · Hydrofluorocarbons · Hydrofluoroolefins · Montreal Protocol

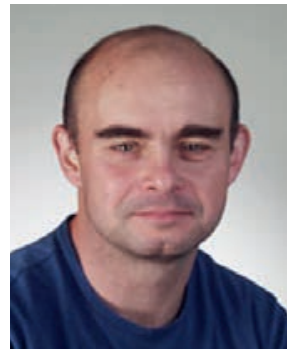

Dr. Stefan Reimann has been involved in the analysis of ozone-depleting gases (e.g. $\mathrm{CFCs}$ ), of reactive trace gases relevant for air pollution (VOCs, $\mathrm{NO}_{\mathrm{x}}$, ozone) and of greenhouse gases $\left(\mathrm{CO}_{2}, \mathrm{CH}_{4}, \mathrm{~N}_{2} \mathrm{O}\right)$ at Empa for more than 20 years. His main interest is in the analysis of halogenated trace gases in the atmosphere, which are measured since 2000 at Jungfraujoch (3540 m asl) as part of the national HALCLIM/CLIMGAS-CH project and within the global AGAGE network (Advanced Global Atmospheric Gases Experiment). Data are used to estimate European and global sources of these trace gases in the atmosphere in order to check for compliance with international treaties, such as the Montreal Protocol and the Kyoto Protocol.

\section{Introduction}

Halogenated organic substances in the atmosphere are often potent greenhouse gases contributing to climate change. ${ }^{[1]}$ In addition, if they contain chlorine or bromine and if they are sufficiently long-lived, they can reach the stratosphere, where they contribute to the depletion of the ozone layer, ${ }^{[2]}$ which shields life on Earth from the UV radiation of the sun. Table 1 gives an overview of four generations of ozone-depleting substances (ODSs) and their substitutes. After the adoption of the Montreal Protocol in 1987, CFCs (chlorofluorocarbons) and very long-lived chlorinated and brominated hydrocarbons, with an atmospheric lifetime of decades to centuries, were gradually disqualified from emissive uses until their global ban in 2010. Initially, they were replaced by HCFCs (hydrofluorochlorocarbons, $2^{\text {nd }}$ generation), which are less harmful to the ozone layer, because they only partially reach the stratosphere due to their shorter lifetime. With the Montreal
Protocol increasingly restricting also the use of these HCFCs, industry began introducing the new class of HFCs (hydrofluorocarbons) in the 1990s. These $3^{\text {rd }}$ generation replacements contain no chlorine anymore and thus do not contribute to the stratospheric ozone depletion, but due to their strong absorption of infrared radiation and their long atmospheric lifetime, they are potent greenhouse gases with high global warming potentials (GWPs).

The growing concern about the ever-increasing market for these HFCs and their potentially considerable contribution to climate change ${ }^{[3]}$ culminated in the Kigali Amendment to the Montreal Protocol, where a phase-down of HFCs to $15 \%$ relative to the current production was agreed upon. This and additional national legislation was the incentive for industry to produce the $4^{\text {th }}$ generation of substitutes, the HFOs (hydrofluoroolefins) or unsaturated HFCs. These molecules contain a carbon double bond, which makes them susceptible to fast degradation in the atmosphere. Consequently, with a lifetime in the range of weeks, their effect on climate is negligible. [3b] Their degradation, however, leads partly to environmentally very stable products (e.g. trifluoroacetic acid), which are mainly deposited by precipitation, ${ }^{[4]}$ are phytotoxic and, hence, in the long term could be potentially harmful to aquatic lifeforms if they, for example, accumulate in landlocked water bodies.

In this article, we present a short overview of the development of the global measurement capacities for halogenated trace gases in the atmosphere and show the distribution of the current network stations. Measurements from these stations are frequently used to estimate trends of the halogenated substances in the atmosphere and their global emissions. Furthermore, we discuss measurements from the high-Alpine background site of Jungfraujoch with substances exclusively detected to be present in the atmosphere for the first time worldwide by Empa. Examples are HFC-245fa, 
Table 1. Four generations of halogenated compounds. Substances are first classified after their ozone-depletion properties (ODPs) and the regulations related to the Montreal Protocol (generations I-III). Second, related to their influence on climate change (generations III-IV), expressed as Global Warming Potentials (GWPs, 100 year time horizon), related to the Kyoto Protocol and the Kigali Amendment of the Montreal Protocol.

\begin{tabular}{|c|c|c|c|c|}
\hline Generation & I & II & III & III \\
\hline Class & $\begin{array}{l}\text { CFC } \\
\text { chlorofluorocarbons }\end{array}$ & $\begin{array}{c}\text { HCFC } \\
\text { hydrochlorofluorocarbons }\end{array}$ & $\begin{array}{c}\text { HFC } \\
\text { hydrofluorocarbons }\end{array}$ & $\begin{array}{c}\text { HFO } \\
\text { hydrofluoroolefins }\end{array}$ \\
\hline Example & $\begin{array}{c}\text { CFC-11 } \\
\text { Trichlorofluoromethane }\end{array}$ & $\begin{array}{c}\text { HCFC-22 } \\
\text { Chlorodifluoromethane }\end{array}$ & $\begin{array}{c}\text { HFC-134a } \\
\text { Tetrafluoroethane }\end{array}$ & $\begin{array}{c}\text { HFO-1234yf } \\
\text { Tetrafluoropropene }\end{array}$ \\
\hline ODP & 1 & 0.05 & 0 & 0 \\
\hline GWP & 4660 & 1760 & 1300 & $<4$ \\
\hline Phase-Out & $\begin{array}{l}\text { Montreal Protocol } \\
\text { 1987-2010 }\end{array}$ & $\begin{array}{l}\text { Montreal Protocol } \\
\text { 1996-2030 }\end{array}$ & $\begin{array}{c}\text { Kyoto Protocol } \\
\text { Montreal Protocol Kigali } \\
\text { Amendment }\end{array}$ & \\
\hline
\end{tabular}

which is used as substitute for the forbidden HCFCs in foam blowing applications, ${ }^{[5]}$ and HFO-1234yf, which is becoming the dominant cooling agent for car air conditioners. ${ }^{6]}$

\section{Development of Measurement Capacities for the Analysis of Atmospheric Halocarbons}

The history of the production of industrial halogenated substances, which were only decades later detected to cause stratospheric ozone-depletion, started in the 1930s, when CFCs were introduced as refrigerants to replace existing toxic compounds (e.g. sulphur dioxide, ammonia). Other uses, such as propellants in spray cans and foam blowing soon followed, and in the early 1970s the dominant use of CFCs was as aerosol in spray cans. Carbon tetrachloride $\left(\mathrm{CCl}_{4}\right)$ was an important starting material for these CFCs, but was also itself extensively used as solvent and fire retardant. For the latter application, $\mathrm{CCl}_{4}$ was eventually replaced by the non-toxic brominated halons. Methyl chloroform $\left(\mathrm{CH}_{3} \mathrm{CCl}_{3}\right)$, another ozone-depleting substance, was introduced as a degreasing solvent, and finally methyl bromide $\left(\mathrm{CH}_{3} \mathrm{Br}\right)$ was used as a very effective fumigant for disinfection of soils and building structures.

Nowadays, all these ozone-depleting substances are banned under the Montreal Protocol because of their damaging effect on stratospheric ozone. However, at the time of their invention they were unquestioned and had the full approval of the scientific and political community. Therefore, first worldwide measurements of CFC-11 performed by Lovelock ${ }^{[7]}$ at Adrigole (Ireland), using a combination of gas chromatography and his newly invented electron caption detector (ECD), were only focusing on CFC-11 as tracer for the declining visibility whenever air from polluted industrial regions in England reached the otherwise pristine Western part of Ireland. Lovelock also provided a first global latitudinal transect of mole fractions for CFC-11 and showed that they were lower in the Southern hemisphere, because of smaller anthropogenic emissions. ${ }^{[8]}$ This opened the door for intense scientific research on the exchange time between the hemispheres and on the lifetimes of the ODSs. Furthermore, a first global network consisting of four stations (ALE, Atmospheric Lifetime Experiment), was set-up and co-sponsored by industry in 1978. [9] This engagement of the industry was strongly motivated by a paper of Molina and Rowland, ${ }^{[2 \mathrm{a}]}$ which suggested that CFCs could destroy strat- ospheric ozone. In addition, NOAA (US National Oceanic and Atmospheric Administration) started a network of global flask measurements at five sites at around the same time, where air is sampled into a glass flask every week and analysed centrally in Boulder (Colorado, USA). This developed into a globally representative network of a total of 15 sites with both flask data and in situ measurements, where samples are taken several times a day and are analysed directly on site. ${ }^{[10]}$

In the 1970s, the effect of CFCs on stratospheric ozone was merely a hypothesis that still lacked real-world observation. Therefore, measurements continued for relatively fundamental scientific reasons. However, when in 1986 the British Antarctic Survey detected the 'ozone hole' in the stratosphere over Antarctica, ${ }^{[11]}$ these networks were well positioned to provide the urgently needed information for quantifying global concentration trends and derived emissions. After the detection of the mechanism for the ozone destruction, as summarised in Hartmann and Watson ${ }^{[12]}$ and in Solomon et al., ${ }^{[13]}$ and after the subsequent adoption of a phase-out scheme for these ODSs in the Montreal Protocol, the observation/monitoring networks were again needed to follow the prescribed decline in emissions and monitor the compliance with the treaty. In the late 1990, the ALE system was expanded and became the Advanced Global Atmospheric Gases Experiment (AGAGE) ${ }^{[14]}$ (Fig. 1). AGAGE included more stations and, in addition to GC-ECD, a new measurement technique which consisted of a pre-concentration unit, coupled to a GC-mass spectrometer (ADS-GC-MS ${ }^{[15]}$ ). This new method allowed not only the measurement of ozone-depleting chlorine and bromine-containing compounds but also of HFCs, as their $3^{\text {rd }}$ generation replacements. Finally, the so-called Medusa GC-MS system was developed ${ }^{[16]}$ and was introduced as a reliable monitoring technique at around 2005, and thereafter rapidly became the backbone of the AGAGE network. In addition to the compounds measured by the ADS-GC-MS, the Medusa system provides quantitative measurements of the most volatile halogenated trace gases, such as $\mathrm{SF}_{6}$ and $\mathrm{CF}_{4}$.

In Switzerland, Empa began measurements of halocarbons at Jungfraujoch using the ADS-GC-MS method in 2000.[17] After upgrading to the new Medusa system in 2008, the station was adopted as a core AGAGE station. ${ }^{[18]}$ Additionally, Empa runs a laboratory Medusa system in Dübendorf. This system provides 


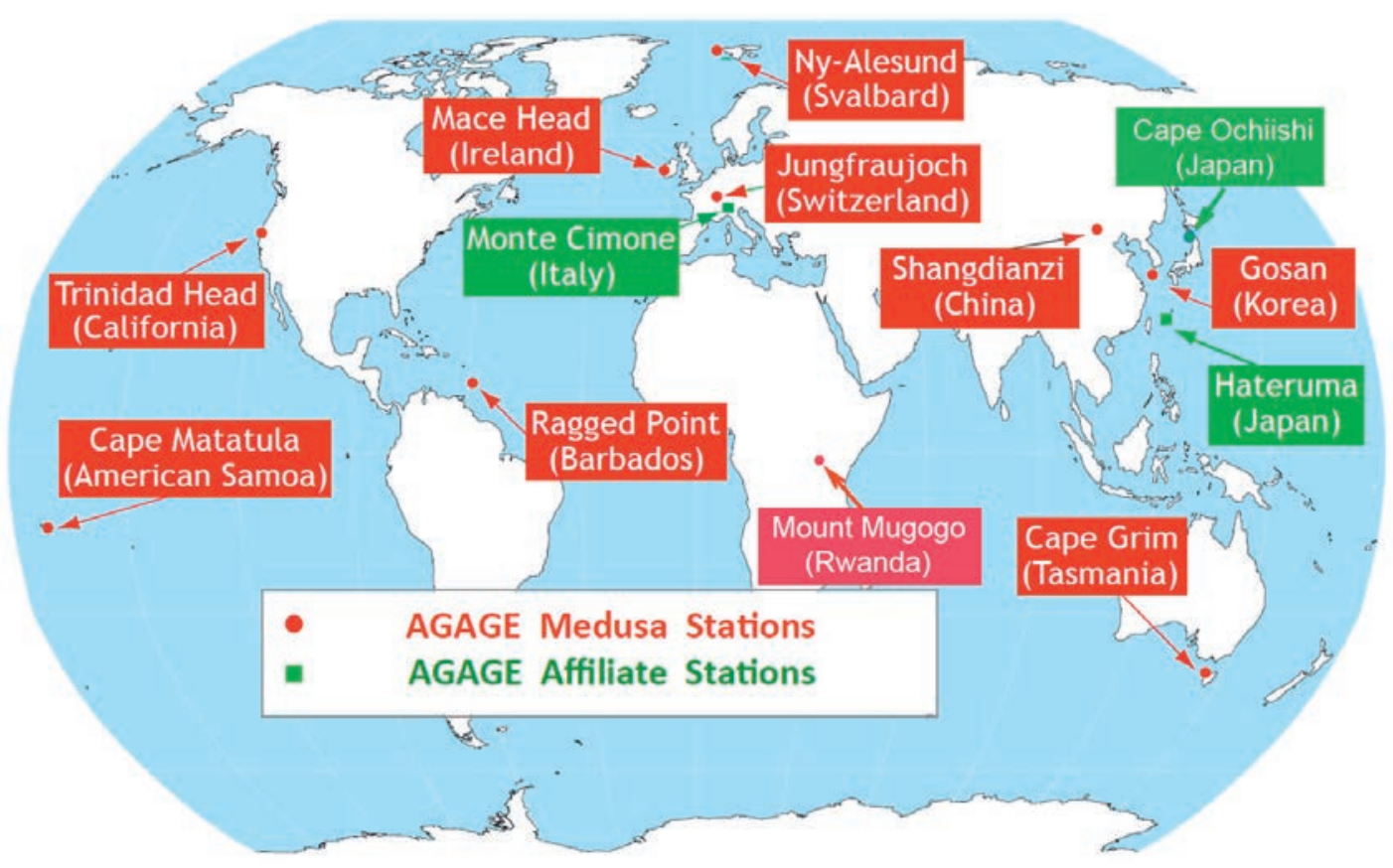

Fig. 1. Location of global measurement network of AGAGE and affiliated sites (continuous, in situ).

key measurements for method development and validation, and for the detection of new atmospheric gases. ${ }^{[6 a]}$ Furthermore, the Medusa-GC-MS in Dübendorf is unique worldwide because it is used for the long-term measurements of the full suite of halogenated compounds in an urban surrounding.

\section{Averaged Global Mole Fractions and Estimated Global Emissions}

In this Section, the evolution of the atmospheric mole fractions of the most important ozone-depleting substances, measured by the AGAGE and NOAA networks, are discussed in relation to the Montreal Protocol. In Fig. 2, the global mole fractions (ppt, parts-per trillion, $1 \times 10^{-12} \mathrm{~mol} / \mathrm{mol}$ ) are shown for three groups of ODSs and the HFCs as substitutes. The succession of generations of ODSs is discussed in Section 3.1 for CFCs and long-lived chlorinated solvents, in Section 3.2 for brominated species (halons and methyl bromide), and in Section 3.3 for HCFCs ( $2^{\text {nd }}$ generation replacement compounds). Finally, the HFCs as $3^{\text {rd }}$ generation replacement compounds are discussed in Section 3.4. In addition, global emissions in 2016 are given in Fig. 2, which were calculated by combining data from NOAA and AGAGE with a global box model.[19]

\subsection{Chlorofluorocarbons (CFCs) and Long-lived Chlorinated Solvents}

In the Montreal Protocol, production of CFCs and long-lived chlorinated solvents for emissive uses was globally phased-out in 1996 and 2010 for industrialised and developing countries, respectively. In Fig. 2A, the growth and decline of the atmospheric mole fractions are shown for CFC-11 $\left(\mathrm{CCl}_{3} \mathrm{~F}\right), \mathrm{CFC}-12$ $\left(\mathrm{CCl}_{2} \mathrm{~F}_{2}\right), \mathrm{CFC}-113\left(\mathrm{C}_{2} \mathrm{Cl}_{3} \mathrm{~F}_{3}\right), \mathrm{CCl}_{4}$ and $\mathrm{CH}_{3} \mathrm{CCl}_{3}$ together with their estimated global emissions in 2016. These substances had the most widespread uses amongst the $1^{\text {st }}$ generation ODSs and hence reached the highest mole fractions in the atmosphere. ${ }^{[20]}$ The maximum for a single compound was reached by CFC-12, which was used as a refrigerant and foam-blowing agent, with more than $540 \mathrm{ppt}$ around 2003. CFC-11, which was used as an aerosol in spray cans and as foam blowing agent, was the ODS with the second highest mole fractions, with values of $\sim 270 \mathrm{ppt}$ in the mid-1990s. The third most important first-generation CFC, CFC-113, was primarily used as a solvent and peaked at slightly over $80 \mathrm{ppt}$ at around the same time.
$\mathrm{CCl}_{4}$ and $\mathrm{CH}_{3} \mathrm{CCl}_{3}$ both had widespread use as chlorinated solvents in metal cleaning and other industrial applications. $\mathrm{CCl}_{4}$ was also the feedstock for the production of $\mathrm{CFCs}$, from where further emissions occurred. Similarly to the $\mathrm{CFCs}, \mathrm{CCl}_{4}$ and $\mathrm{CH}_{3} \mathrm{CCl}_{3}$ also reached their peak mole fractions in the $1990 \mathrm{~s}$, with $105 \mathrm{ppt}$ and $130 \mathrm{ppt}$, respectively. With a maximum of nearly $700 \mathrm{Gg} /$ $\mathrm{yr}(\mathrm{kt} / \mathrm{yr}), \mathrm{CH}_{3} \mathrm{CCl}_{3}$ had the highest emissions of all ODSs in the early 1990s. Since then, emissions have decreased dramatically, as have atmospheric mole fractions, because $\mathrm{CH}_{3} \mathrm{CCl}_{3}$ has a lifetime of only five years, which is very small compared to other strong ODSs. Emissions of $\mathrm{CCl}_{4}$ in 2016 were still surprisingly high for a substance for which emissive uses had been forbidden globally since 2010 . Consequently, a recent study found on-going emissions as a by-product from the production of permitted chlorinated solvents, such as $\mathrm{CH}_{2} \mathrm{Cl}_{2}$ and $\mathrm{CHCl}_{3} \cdot{ }^{[21]}$ For $\mathrm{CFCs}$, current emissions are also mirroring the historic uses, with those from CFC-11 being considerably higher than for the other first generation ODSs, which is related to large existing banks (builtin substances) in insulation foams that slowly diffuse into the atmosphere. In addition, recent studies showed new production and emissions of CFC-11 from East Asia and China, ${ }^{[22]}$ which are most probably indicative of a severe violation of the Montreal Protocol.

\subsection{Brominated Ozone-depleting Substances}

Mole fractions of the brominated ODSs are shown in Fig. 2B. Two groups are distinguished in terms of the Montreal Protocol. Whereas long-lived brominated halons, used in fire extinguishing systems, are fully anthropogenic, methyl bromide $\left(\mathrm{CH}_{3} \mathrm{Br}\right)$ has both anthropogenic and natural sources. The most important halons are $\mathrm{H}-1211\left(\mathrm{CBrClF}_{2}\right)$, used in portable fire extinguishers and $\mathrm{H}-1301\left(\mathrm{CBrF}_{3}\right)$ in stationary applications (e.g. computer centres and airplanes). Production of halons for emissive uses was also globally banned in 2010. However, existing installations (banks) are partly exempted from recycling and reuse purposes (e.g. in airplanes). Nevertheless, restrictions led to a peak in mole fractions around 2005 for $\mathrm{H}-1211$ and in the most recent years for H-1301.

The most important anthropogenic source of $\mathrm{CH}_{3} \mathrm{Br}$ was its application as pesticide in agriculture. After its ban, mole fractions declined from $\sim 9 \mathrm{ppt}$ in the late 1990s to currently $\sim 7 \mathrm{ppt}$ (Fig. 2B). However, $\mathrm{CH}_{3} \mathrm{Br}$ is still allowed in so-called quarantine 

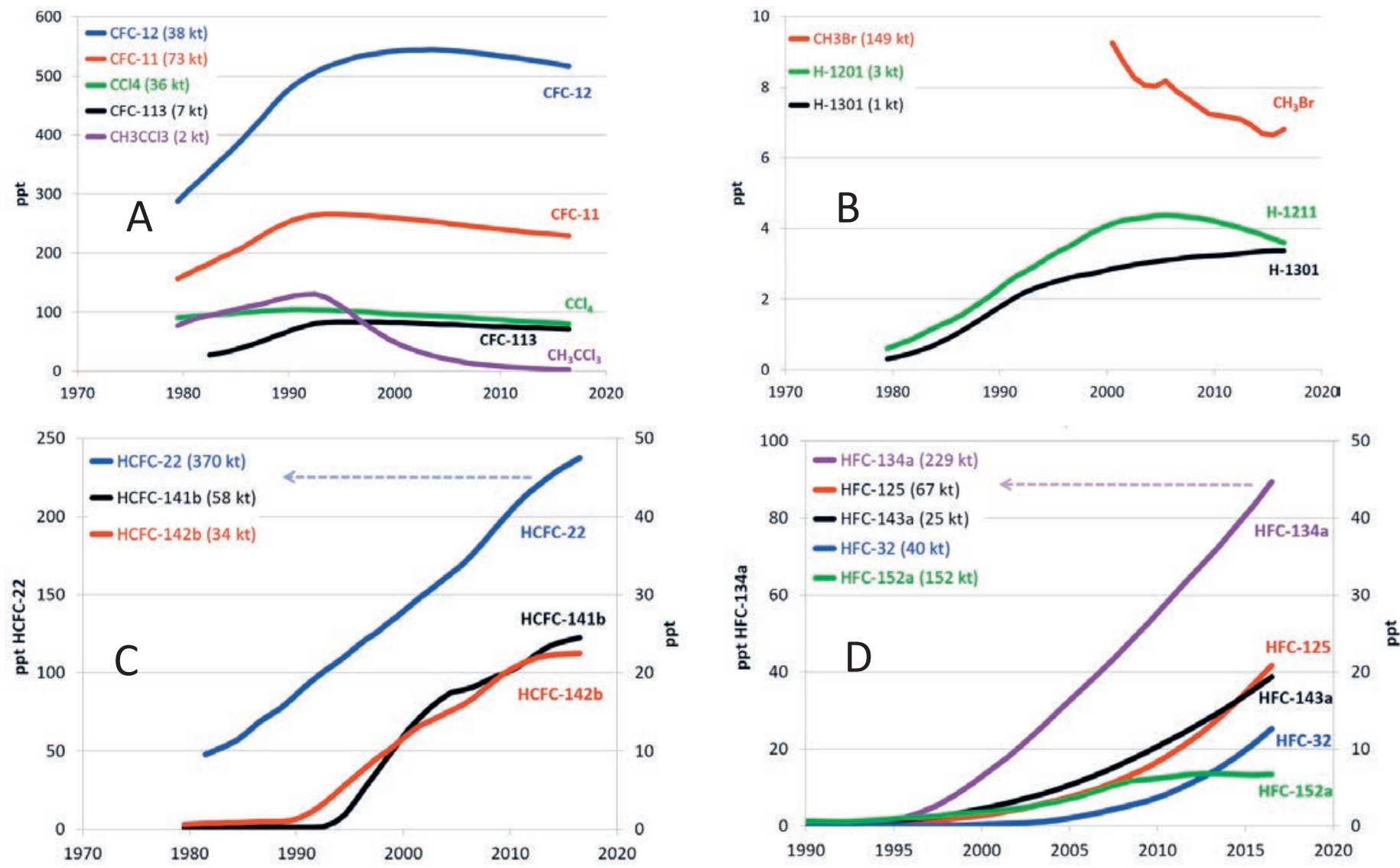

Fig. 2. Globally averaged mole fractions and derived worldwide emissions in 2016 (in parentheses) from the AGAGE global network and archived air samples: A) long-lived CFCs and the chlorinated solvents; B) brominated substances; C); HCFCs; D) HFCs. ${ }^{[3 b, 20,28]}$

and pre-shipment applications (e.g. fumigation of wooden pallets for trade purposes). Corresponding emissions are about $10 \mathrm{Gg} /$ $\mathrm{yr}$, which is, however, small in comparison to the natural sources.

\subsection{Hydrochlorofluorocarbons (HCFCs) - The Second Generation}

$\mathrm{HCFC}-22\left(\mathrm{CHClF}_{2}\right), \mathrm{HCFC}-141 \mathrm{~b}\left(\mathrm{C}_{2} \mathrm{H}_{2} \mathrm{Cl}_{2} \mathrm{~F}\right)$ and $\mathrm{HCFC}-142 \mathrm{~b}$ $\left(\mathrm{C}_{2} \mathrm{H}_{3} \mathrm{ClF}_{2}\right)$ are the three most widely used $\mathrm{HCFCs}$ (Fig. 2C). They initially replaced the most dangerous ODSs in stationary air conditioners (HCFC-22) and in foam blowing applications (HCFC141b, HCFC-142b). As they are still ozone-depleting substances, restrictions under the Montreal Protocol were initiated by a freeze in production for non-emissive uses in 1996 for developed countries and in 2013 for developing countries, with a nearly complete ban of production and consumption for emissive uses in 2020 for the developed countries and by 2030 for developing countries.

HCFCs were already forbidden from usage in foam blowing in developed countries in 2003, noticeable as a short-term dip in otherwise increasing mole fractions and global emissions at that time. Shortly afterwards, however, new production capacities in developing countries led to a temporary increase in global emissions, as seen, for example, for HCFC-141b and HCFC-142b. ${ }^{[23]}$ As a consequence, a global cap in production came into force by an amendment of the Montreal Protocol in 2013. In 2016, emissions of HCFC-22 were considerably higher than for the other two HCFCs and with $370 \mathrm{Gg} / \mathrm{yr}$ comparable to those from the CFCs before the restrictions of the Montreal Protocol took place.

\subsection{Hydrofluorocarbons (HFCs) - The Third Generation}

Contrary to the ozone-depleting substances discussed in the preceding sections, the atmospheric levels of HFCs are still growing rapidly (Fig. 2D). The highest mole fraction has been reached by HFC-134a, which is globally used in car air conditioners. Emissions in 2016 were reaching a level comparable to CFCs be- fore the ban. The other HFCs are used for air conditioning or for foam blowing purposes, but both their mole fractions and emissions are considerably lower. HFC-152a has stabilised in the last years as emissions have declined and the substance's lifetime is only 1.5 years, in comparison to those of the other HFCs, which have lifetimes of about 10 years. The increase in HFC mole fractions in the last decade will likely be halted in the near future when the restrictions of the Kigali Amendment to the Montreal Protocol will lead to considerable reductions in production and emission and replacements with hydrofluoroolefins (see Section 5).

\section{HFCs First Measured at Jungfraujoch}

At Jungfraujoch, several HFCs have been measured for the first time in the atmosphere. Thereby a suspect screening approach was applied, with a priori information from industry that these substances were actually in use as replacement compounds. The first example is the detection of HFC-365mfc in 2003.[24] This compound was used as a foam-blowing agent, replacing the banned HCFCs and CFCs. HFC-365mfc was followed by the first detection of HFC-245fa, ${ }^{[5]}$ and HFC-227ea and HFC236fa. ${ }^{[25]}$ Most recently, halogenated anaesthetics were detected by Empa to be globally present in the atmosphere, reaching the most remote places, such as Antarctica. ${ }^{[26]}$ In Fig. 3, the record of HFC-245fa from Jungfraujoch is shown in combination with other European AGAGE sites at Mace Head (Ireland) and NyAlesund (Spitsbergen). Whereas pollution events are clearly visible for Jungfraujoch in the middle of the continent, the station at Spitsbergen mainly records the Northern hemispheric background. HFC-245fa emissions mainly occur due to losses during the production of foams. When measurements during pollution events at Jungfraujoch and at Mace Head are combined with the history of the air masses arriving at the site, it is possible to assess important regional source regions. ${ }^{[27]}$ Results for HFC-245fa show that Spain and Northern Italy were the only source regions 
until around 2010. Afterwards, emissions occurred also in the Benelux area.

\section{HFOs - Fourth Generation Replacement Compounds - First Measured in Switzerland}

HFOs (hydrofluoroolefins) are unsaturated HFCs with a short atmospheric lifetime. Several HFOs are newly produced by industry in order to reduce the climate effect of the long-lived HFCs as foreseen in the Kigali Amendment of the Montreal Protocol. At Jungfraujoch, Empa began measurements of three HFOs (HFO1234yf, HFO-1234ze(E), HCFO-1233zd(E)) in 2011. Since the production of these compounds had barely started, they initially remained undetected, i.e. their mole fraction was below their respective detection limits. However, more and more frequently, periods with measurable mole fractions occurred in later years, and currently these compounds are observed in the majority of the samples at Jungfraujoch (Fig. 4).

\section{Conclusion}

Long-term analysis of substances that lead to the destruction of stratospheric ozone have been crucial for verifying the global ban on production and usage by the Montreal Protocol on Substances that Deplete the Ozone Layer. The station at Jungfraujoch, where these substances have been measured since 2000, is an important part of this global network of stations. In addition, air sampled at Jungfraujoch is not only used for recording concentrations during background conditions, but also for assessing European emissions, during events when air from the surrounding industrialised areas in Europe is advected. The on-going and long-term need for a globally representative measurement network has recently been shown by the detection of new emissions of the previously forbidden CFC-11 from East Asia and China. ${ }^{[22]}$ In the future, new regulations under the Kigali Amendment will lead to a substantial down-sizing also of climate-forcing HFCs. Again, as for CFCs, global measurements will be essential for assessing the success of the treaty and estimate regional and global emissions.

\section{Acknowledgements}

Operations at Jungfraujoch were supported by the Swiss National Program HALCLIM/CLIMGAS-CH (Swiss Federal Office for the Environment, FOEN) and by the International Foundation High Altitude Research Stations Jungfraujoch and Gornergrat (HFSJG). Further contribution to the measurements is acknowledged from Swiss National Science Foundation under the project IHALOME (200020_175921).

Received: November 20, 2019

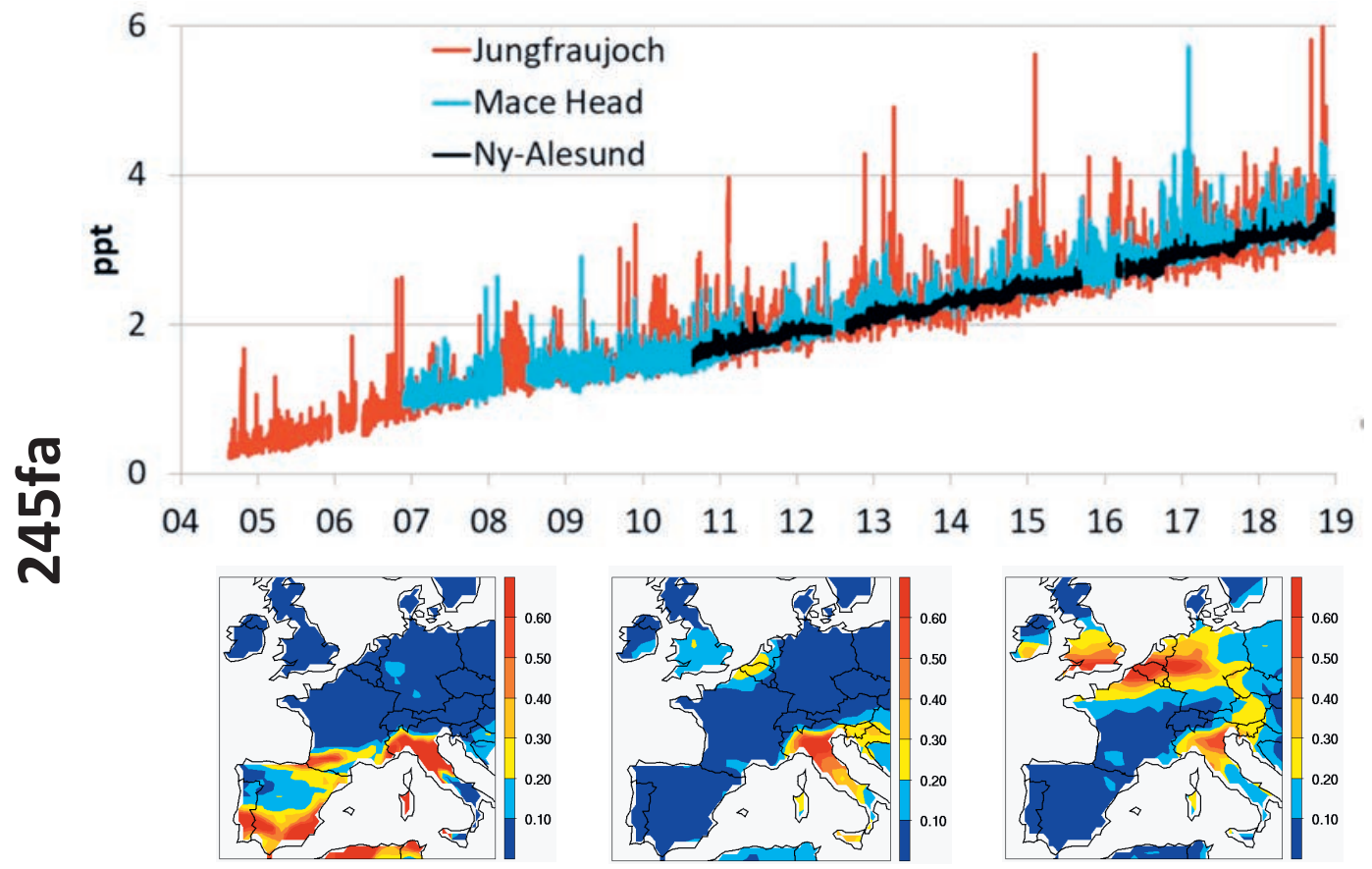

Fig. 3. HFC-245 with first measurements at Jungfraujoch (Switzerland, 2004-19) followed by Mace Head (Ireland, 2007-19 and Ny-Alesund (Spitsbergen, 2010-19). Maps show potential source regions related to peak events in the periods indicated with grey bars.

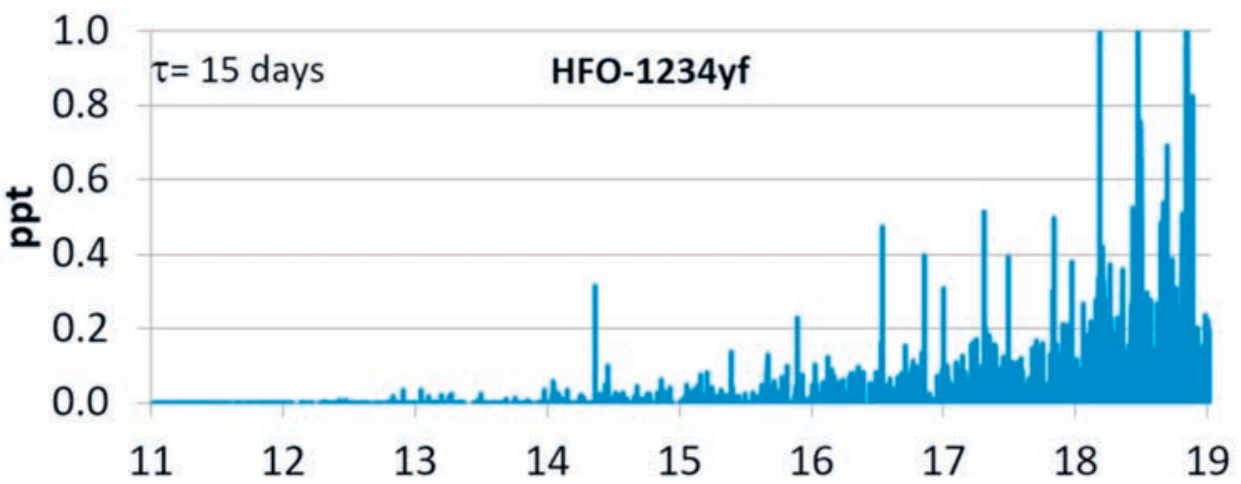

Fig. 4. HFO-1234yf measurement data from Jungfraujoch since 2011. HFO-1234yf was not detectable in the beginning of the record but shows more and more a stable background concentration also in very clean air masses. 
[1] G. Myhre, D. Shindell, F.-M. Bréon, W. Collins, J. Fuglestvedt, J. Huang, D. Koch, J.-F. Lamarque, D. Lee, B. Mendoza, T. Nakajima, A. Robock, G. Stephens, T. Takemura, H. Zhang, 'Climate Change 2013: The Physical Science Basis. Contribution of Working Group I to the Fifth Assessment Report of the Intergovernmental Panel on Climate Change', 2013, Cambridge University Press.

[2] a) M. J. Molina, F. S. Rowland, Nature 1974, 249, 810, DOI: 10.1038/249810a0; b) WMO, 'Global Ozone Research and Monitoring Project-Report No. 58', 2018.

[3] a) G. J. M. Velders, A. R. Ravishankara, M. K. Miller, M. J. Molina, J. Alcamo, J. S. Daniel, D. W. Fahey, S. A. Montzka, S. Reimann, Science 2012, 335, 922, DOI: 10.1126/science.1216414; b) S. A. Montzka, G. J. M. Velders, 'World Meteorological Organization Global Ozone Research and Monitoring Project - Report No. 55, Scientific Assessment of Ozone Depletion', 2018, Chap. 2.

[4] S. Henne, D. E. Shallcross, S. Reimann, P. Xiao, D. Brunner, S. O'Doherty, B. Buchmann, Environ. Sci. Technol. 2012, 46, 1650, DOI: 10.1021/ es2034608.

[5] M. K. Vollmer, S. Reimann, D. Folini, L. W. Porter, L. P. Steele, Geophys. Res. Lett. 2006, 33, doi:10.1029/2006GL026763.

[6] a) M. K. Vollmer, S. Reimann, M. Hill, D. Brunner, Environ. Sci. Technol. 2015, 49, 2703, DOI: 10.1021/es505123x; b) M. K. Vollmer, S. Reimann, M. Hill, B. Buchmann, L. Emmenegger, Chimia 2016, 70, 365, DOI: 10.2533/ chimia.2016.365.

[7] J. E. Lovelock, Atmos. Environ. 1972, 6, 917, DOI: 10.1016/00046981(72)90100-X

[8] J. E. Lovelock, R. J. Maggs, R. J. Wade, Nature 1973, 241, 194, DOI: $10.1038 / 241194 \mathrm{a} 0$

[9] R. G. Prinn, P. G. Simmonds, R. A. Rasmussen, R. D. Rosen, F. N. Alyea, C A. Cardelino, A. J. Crawford, D. M. Cunnold, P. J. Fraser, J. E. Lovelock, J. Geophys. Res.: Oceans 1983, 88, 8353, DOI: 10.1029/JC088iC13p08353.

[10] J. W. Elkins, T. M. Thompson, T. H. Swanson, J. H. Butler, B. D. Hall, S. O. Cummings, D. A. Fishers, A. G. Raffo, Nature 1993, 364, 780, DOI: 10.1038/364780a0

[11] J. C. Farman, B. G. Gardiner, J. D. Shanklin, Nature 1985, 315, 207, DOI $10.1038 / 315207 \mathrm{a} 0$.

[12] D. Hartmann, R. T. Watson, 'Report of the International Ozone Trends Pane 1988, World Meteorological Organization Global Ozone Research and Monitoring Project-Report No. 18', 1988, pp 665-750.

[13] S. Solomon, 'Scientific Assessment of Stratospheric Ozone: 1989. World Meteorological Organization Global Ozone Research and Monitoring Project-Report No. 20', 1989, pp 1-161.

[14] R. G. Prinn, R. F. Weiss, P. J. Fraser, P. G. Simmonds, D. M. Cunnold, F. N. Alyea, S. O'Doherty, P. Salameh, B. R. Miller, J. Huang, R. H. J. Wang, D. E. Hartley, C. Harth, L. P. Steele, G. Sturrock, P. M. Midgley, A. McCulloch, J. Geophys. Res.: Atmospheres 2000, 105, 17751, DOI 10.1029/2000jd900141.

[15] P. G. Simmonds, S. O’Doherty, G. Nickless, G. A. Sturrock, R. Swaby, P Knight, J. Ricketts, G. Woffendin, R. Smith, Anal. Chem. 1995, 67, 717, DOI: $10.1021 / \mathrm{ac} 00100 \mathrm{a} 005$.

[16] B. R. Miller, R. F. Weiss, P. K. Salameh, T. Tanhua, B. R. Greally, J. Muhle, P. G. Simmonds, Anal. Chem. 2008, 80, 1536, DOI: 10.1021/ac702084k

[17] S. Reimann, D. Schaub, K. Stemmler, D. Folini, M. Hill, P. Hofer, B. Buchmann, P. G. Simmonds, B. R. Greally, S. O'Doherty, J. Geophys. Res.: Atmospheres 2004, 109, art. no., DOI: 10.1029/2003JD003923.

[18] R. G. Prinn, R. F. Weiss, J. Arduini, T. Arnold, H. L. DeWitt, P. J. Fraser, A. L. Ganesan, J. Gasore, C. M. Harth, O. Hermansen, J. Kim, P. B. Krummel, S. Li, Z. M. Loh, C. R. Lunder, M. Maione, A. J. Manning, B. R. Miller, B. Mitrevski, J. Mühle, S. O’Doherty, S. Park, S. Reimann, M. Rigby, T. Saito,
P. K. Salameh, R. Schmidt, P. G. Simmonds, L. P. Steele, M. K. Vollmer, R. H. Wang, B. Yao, Y. Yokouchi, D. Young, L. Zhou, Earth Syst. Sci. Data Discuss. 2018, 2018, 1, DOI: 10.5194/essd-2017-134.

[19] a) D. M. Cunnold, P. J. Fraser, R. F. Weiss, R. G. Prinn, P. G. Simmonds, B. R. Miller, F. N. Alyea, A. J. Crawford, J. Geophys. Res.: Atmospheres 1994, 99, 1107, DOI: 10.1029/93JD02715; b) M. Rigby, R. G. Prinn, S. O’Doherty, S. A. Montzka, A. McCulloch, C. M. Harth, J. Muhle, P. K. Salameh, R. F. Weiss, D. Young, P. G. Simmonds, B. D. Hall, G. S. Dutton, D. Nance, D. J. Mondeel, J. W. Elkins, P. B. Krummel, L. P. Steele, P. J. Fraser, Atmos. Chem. Phys. 2013, 13, 2691, DOI: 10.5194/acp-13-2691-2013.

[20] A. Engel, M. Rigby, 'Scientific Assessment of Ozone Depletion: 2018, World Meteorological Organization Global Ozone Research and Monitoring Project-Report No. 58', 2018, Chap. 1.

[21] D. Sherry, A. McCulloch, Q. Liang, S. Reimann, P. A. Newman, Environ. Res. Lett. 2018, 13, 024004, DOI: 10.1088/1748-9326/aa9c87.

[22] a) S. A. Montzka, G. S. Dutton, P. F. Yu, E. Ray, R. W. Portmann, J. S. Daniel, L. Kuijpers, B. D. Hall, D. Mondeel, C. Siso, D. Nance, M. Rigby, A. J. Manning, L. Hu, F. Moore, B. R. Miller, J. W. Elkins, Nature 2018, 557, 413, DOI: 10.1038/s41586-018-0106-2; b) M. Rigby, S. Park, T. Saito, L. M. Western, A. L. Redington, X. Fang, S. Henne, A. J. Manning, R. G. Prinn, G. S. Dutton, P. J. Fraser, A. L. Ganesan, B. D. Hall, C. M. Harth, J. Kim, K. R. Kim, P. B. Krummel, T. Lee, S. Li, Q. Liang, M. F. Lunt, S. A. Montzka, J. Muhle, S. O'Doherty, M. K. Park, S. Reimann, P. K. Salameh, P. Simmonds, R. L. Tunnicliffe, R. F. Weiss, Y. Yokouchi, D. Young, Nature 2019, 569, 546, DOI: 10.1038/s41586-019-1193-4.

[23] S. A. Montzka, B. D. Hall, J. W. Elkins, Geophys. Res. Lett. 2009, 36, L03804, DOI: 10.1029/2008GL036475.

[24] K. Stemmler, D. Folini, S. Ubl, M. K. Vollmer, S. Reimann, S. O. Doherty, B. R. Greally, P. G. Simmonds, A. J. Manning, Environ. Sci. Technol. 2007, 41, 1145, DOI: 10.1021/es061298h.

[25] M. K. Vollmer, B. R. Miller, M. Rigby, S. Reimann, J. Muhle, P. B. Krummel, S. O’Doherty, J. Kim, T. S. Rhee, R. F. Weiss, P. J. Fraser, P. G. Simmonds, P. K. Salameh, C. M. Harth, R. H. J. Wang, L. P. Steele, D. Young, C. R. Lunder, O. Hermansen, D. Ivy, T. Arnold, N. Schmidbauer, K. R. Kim, B. R. Greally, M. Hill, M. Leist, A. Wenger, R. G. Prinn, J. Geophys. Res.: Atmospheres 2011, 116, DOI: 10.1029/2010jd015309.

[26] M. K. Vollmer, T. S. Rhee, M. Rigby, D. Hofstetter, M. Hill, F. Schoenenberger, S. Reimann, Geophys. Res. Lett. 2015, 42, 1606, DOI: 10.1002/2014GL062785.

[27] D. Brunner, S. Henne, C. A. Keller, S. Reimann, M. K. Vollmer, S. O'Doherty, M. Maione, Atmos. Chem. Phys. 2012, 12, 3455, DOI: 10.5194/ acp-12-3455-2012.

[28] S. Reimann, J. W. Elkins, P. J. Fraser, B. D. Hall, M. J. Kurylo, E. Mahieu, S. A. Montzka, R. G. Prinn, M. Rigby, P. G. Simmonds, R. F. Weiss, Comptes Rendus Geosci. 2018, 350, 384, DOI: 10.1016/j.crte.2018.08.008.

\section{License and Terms}

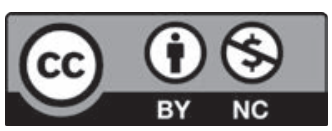

This is an Open Access article under the terms of the Creative Commons Attribution License CC BY_NC 4.0. The material may not be used for commercial purposes.

The license is subject to the CHIMIA terms and conditions: (http:// chimia.ch/component/sppagebuilder/?view=page \&id=12).

The definitive version of this article is the electronic one that can be found at doi:10.2533/chimia.2020.136 